\title{
Um intelectual sem concessões
}

Fabio Mascaro Querido ${ }^{I}$

R Oberto Schwarz não é um intelectual usual, daqueles que nadam no sentido da corrente. Bem ao contrário. No limite, a sua trajetória pode ser vista como a explicitação de um modelo de trabalho intelectual que, dos anos 1960 até os dias de hoje, foi sendo cada vez mais colocado em questão. Pode-se mesmo dizer que a reflexão schwarziana foi ganhando intensidade em medida inversamente proporcional ao declínio (no Brasil e no mundo) da figura do intelectual crítico irredutível às posições estabelecidas, mas antenado com o debate público do seu presente - figura com a qual ele sempre se identificou.

Abarcando mais de cinco décadas de atividade, seu novo livro, Seja como for, dá um testemunho significativo desse itinerário singular, seja por meio da exposição do seu próprio pensamento, sejam por meio de comentários ou retratos de intelectuais com quem manteve alguma interlocução. Nesse que é o seu nono livro de crítica (afora dois de poesia e uma peça de teatro), Schwarz se faz presente em toda a sua plenitude espiritual. O livro compila materiais preciosos, alguns dos quais até então relegados ao segundo plano, a despeito da importância que têm na decifração de nuances do pensamento do autor comumente desprezadas pelas leituras impressionistas, que não apreendem senão o sentido literal do texto.

Pode-se destacar, por exemplo, a entrevista concedida a Maria Rita Kehl e Fernando Haddad, publicada na revista Teoria e Debate em 1994, ou a longa entrevista a Eva Corredor, também de
1994, em que Schwarz coloca nos seus devidos termos o papel de Lukács na sua atividade crítica: mais do que modelo normativo de análise, o esquema lukacsiano do Realismo (com maiúscula) atuava como ponto de partida diferenciador, ou seja, como aquilo que não pode ser num país da periferia do capitalismo como o Brasil. Ou ainda a entrevista a Louzada Filho e Gildo Marçal Brandão, publicada originalmente na revista Encontros com a Civilização Brasileira, em 1979.

Sem falar no relatório da polícia política da ditadura militar sobre o ensaio "Cultura e política", ou na carta inédita em que conta ao mestre Antonio Candido as peripécias da sua defesa de doutorado em Paris, com um dos membros avaliadores tendo se recusado a avalizar a tese, acusando-o de apresentar um trabalho incompreensível - algo semelhante ao que havia se passado com Walter Benjamin na Alemanha, em 1925, salvo o desfecho diferente, já que, no caso de Schwarz, o obstinado avaliador acabou por se retirar da banca, que enfim aprovou o trabalho.

Pela dispersão temática, Seja como for não é leitura fácil. Schwarz quase sempre fala por meio dos outros, pensando através da cabeça alheia - ao quadrado, por assim dizer (Querido, 2019b). À procura de alguma unidade, o quebra-cabeças precisa ser permanentemente remontado pelo leitor. Esse caráter fragmentado é, porém, sintomático do modelo de atividade crítica acalentado pelo próprio autor. À exceção de sua tese de doutorado (que pouco segue os manuais 
acadêmicos, aliás), e do segundo estudo sobre Machado de Assis (Um mestre na periferia do capitalismo), os livros de Schwarz são todos compilações de ensaios específicos, em torno de um tema ou de autor determinado. Foi por meio dessa crítica em pílulas que Schwarz foi galgando a sua posição no cenário intelectual brasileiro.

Uma inflexão decisiva na trajetória do autor se deu no final dos anos 1960. Schwarz havia se formado em ciências sociais no final da década de 1950, na mesma turma de Michael Löwy (a quem já havia conhecido nas redes de sociabilidade judaica), Francisco Weffort e Heleieth Saffioti. Na mesma época, participou do chamado Seminário d'O Capital, junto a jovens professores como $\mathrm{F}$. $\mathrm{H}$. Cardoso, O. Ianni e José Artur Giannotti. Estimulado por Candido, fez o mestrado em Teoria Literária, em Yale, nos Estados Unidos, entre 1961 e 1963 , para depois trabalhar como professor assistente na cadeira de Teoria Literária e Literatura Comparada na USP.

É nesse contexto que publica o seu primeiro livro de ensaios, $A$ sereia e o desconfiado, em 1965 - em 1959 havia publicado o livro de poesias, Pássaro na gaveta, pela Massao Ohno, editora dos escritores marginais e da boemia paulistana. Em 1969, em meio à radicalização da repressão resultante da proclamação do AI-5 em dezembro de 1968, decide se exilar na França, saindo do país pela fronteira com o Uruguai. Além de professor, o jovem crítico era um dos editores da revista Teoria e Prática, cujo último número havia sido confiscado pela polícia.

A experiência do exílio em Paris no itinerário de Schwarz não pode ser subestimada, como se faz amiúde, inclusive (parcialmente) pelo próprio autor, que prefere apontar o rol das suas influências intelectuais, entre elas a de seus professores da USP nos anos 1950 (cf. p.ex.: p.102). Ora, mais importante do que enumerar as influências recebidas é compreender a gênese social dessas incorporações, assim como a maneira como elas são traduzidas à luz do objeto em questão. Nesse sentido, ainda que desde a virada para os anos 1960 Schwarz já tenha tomado contato com os autores com o auxílio dos quais armaria o seu modelo crítico (Lukács, Brecht, Benjamin, Adorno, de um lado, e Candido, F. H. Cardoso e F. Novais, de outro), seria apenas no exílio francês, a partir de 1969, que ele os mobilizaria para a elucidação de um problema especificamente seu, qual seja: o da relação entre formas literárias (ou culturais) e matéria histórico-social num país da periferia do capitalismo como o Brasil.

Basta comparar, por exemplo, os ensaios compilados em A sereia e o desconfiado com os de O pai de família e outros estudos (1978), ou, mais ainda, com a tese de doutorado defendida na França em 1976, e publicada em livro no ano seguinte, no Brasil, com o título Ao vencedor as batatas. Enquanto nos ensaios do primeiro livro, escritos antes do golpe de 1964, o jovem crítico buscava aferir a coerência formal de um autor ou de uma obra à luz de uma concepção normativa (de matriz lukacsiana) do que deveria ser, genericamente, um bom romance ou uma boa obra de arte, nos trabalhos subsequentes, concebidos no exílio - e sob o impacto de uma ditadura militar que se mostrara mais economicamente modernizadora e mais duradoura do que parecia-, o objetivo foi pensar as formas (literárias ou culturais) como materiali- 
zações da experiência histórica brasileira.

Do plano mais abstrato das ideologias se passa então à consideração materialista da relação entre forma e substrato histórico-social, tarefa para a qual a noção adorniana de forma objetiva se mostrava mais operacional do que a visão normativamente carregada do romance realista explicitada no modelo lukacsiano. A análise da literatura ou da cultura implicava agora a elaboração simultânea de uma visão sobre o processo histórico-social brasileiro. "Toda forma é forma de alguma coisa" (p.157). Por meio da crítica literária, e da análise dos romances de Machado de Assis em particular, é uma nova interpretação do Brasil que se desdobra. Nesse sentido, é possível dizer que o Brasil emerge de fato, na reflexão schwarziana, durante o exílio francês. Judeu-austríaco de origem, o crítico precisou voltar ao velho continente, espremido pelas contingências políticas do presente, para redescobrir (agora conceitualmente, por assim dizer) o Brasil.

A chave dessa interpretação do Brasil pode ser localizada no modo como Schwarz analisa a aclimatação das ideias modernas pelas elites brasileiras do século XIX, com ressonâncias nos rumos posteriores da modernidade no país. A primeira vez que esse tópico veio à tona foi no conhecido ensaio "As ideias fora do lugar", de 1972, que figuraria como capítulo introdutório da tese de doutorado. Para Schwarz, as ideias modernas pareciam fora do lugar, no Brasil, em função do descolamento entre o receituário doutrinário propalado e a estrutura social do país. E pareciam fora do lugar não por algum problema congênito das ideias liberal-modernas em si, mas sim pelo fato de que essas ideias não impactavam de modo efetivo a vida da maior parte da população, que ficava apartada da modernidade proclamada.

Sob esse ponto de vista, diga-se de passagem, o casamento atual entre liberalismo econômico e reacionarismo societal deixa de ser visto como um ponto fora da curva para ser tratado, antes, como a expressão mais radical e, portanto, mais perversa, de uma tradição histórica - materializada no modo de ser de nossas elites - que remonta às origens da inserção do Brasil na modernidade emergente.

Além de nacional, trata-se de uma questão de classe. Era do interesse das classes dominantes absorver e imitar as ideologias modernas ao mesmo tempo em que se mantinham intactas a vida social no "Brasil real". Inversamente, é do interesse das classes dominadas "se aferrar à problemática local e fazer com que ela apareça” (p.39). No plano intelectual, viria daí o "lado forte do nacionalismo", ou seja, dessa disposição "em apanhar as experiências e contradições brasileiras tais quais elas se apresentam aqui, e não através de uma categorização elaborada noutra parte" (p.38, 39).

$\mathrm{Na}$ entrevista concedida à revista $M \mathrm{M}^{-}$ vimento, em 1976, e reproduzida no livro, Schwarz reconhece que "as próprias ideologias libertárias", dentre elas o marxismo, "são com frequência uma ideia fora do lugar, é só deixam de sê-lo quando se reconstroem a partir de contradições locais" (p.24). Desde que purgada de suas ilusões provincianas, a posição nacionalista poderia contribuir, portanto, para que a crítica marxista se reconstrua a partir da problemática nacional, rompendo com todo universalismo abstrato. Assim, tal crítica estaria em condições de superar a dicotomia outrora esquadrinhada no ensaio " $\mathrm{Na}$ - 
cional por subtração" (1986) - a saber: aquela entre nacionalismo (autoritário) e cosmopolitismo (liberal), ou entre localismo e globalismo -, traduzindo as categorias “universais" à luz da problemática local, ao mesmo tempo em que vê nesta um momento do desenvolvimento desigual e combinado do capitalismo.

Nesse processo, a crítica amplia o seu escopo, ganhando novas perspectivas, ligadas ao ponto de vista da periferia - não sendo nem localista, pois não dispensa a mirada universalizante, nem cosmopolita, já que a conceituação se subordina à matéria local, e não o contrário. A crítica é periférica porque reconhece o primado do objeto, quer dizer, o primado da matéria social brasileira. Mas ela é universal porque interpela a totalidade do sistema a partir não apenas de uma posição social, senão também de uma posição geopolítica específica, na qual as ideologias europeias funcionam em outro diapasão.

A explicitação desse ponto de vista crítico da periferia, de alcance global, é talvez a principal contribuição intelectual de Roberto Schwarz. Não por acaso, esse é um tópico recorrente em Seja como for, em especial nas entrevistas e retratos redigidos a partir da virada para os anos 1990. Desde então, ao tema da universalidade do ponto de vista periférico se soma aquele da sua atualidade, em meio ao processo de desagregação mais ou menos generalizada das sociedades nacionais não apenas na periferia, o que nada teria de surpreendente, mas também no centro do capitalismo. Daí a atualidade da perspectiva periférica: o que é novidade e exceção para alguns países do centro sempre fora regra geral naqueles da periferia.

A dependência material se transmuta em vantagem cognitiva, e é por isso que não seria exagero, hoje, situar Schwarz entre as grandes figuras intelectuais do mundo nos últimos 30 ou 40 anos. Especialmente quando se tem em conta o eclipse contemporâneo do tipo de intelectual crítico que ele representa. Muito embora tenha cumprido todos os requisitos da carreira acadêmica, tendo se tornado professor titular na Unicamp, Schwarz jamais abandonou um modelo de crítica (ensaística) infenso à especialização universitária - um modelo de crítica muitas vezes censurado por seu elitismo, à medida que a sua mise-en-scène dependeria quase que exclusivamente do cabedal de referências culturais do próprio crítico, arbitrariamente livre para dizer o que quiser e, o que é pior, como quiser.

Parafraseando Russel Jacoby (1990), Schwarz estaria entre os "últimos intelectuais" que ainda resistem em meio à atmosfera cindida entre as amarras acadêmicas e o recuo identitário. Defende a independência intelectual, mas não como álibi de uma posição olímpica diante do mundo, e sim como escudo contra as pressões do engajamento pragmático, materializado na ascensão do outrora intelectual de esquerda Fernando Henrique Cardoso à presidência da República em 1995. Esse resguardo de autonomia, que exige alta voltagem do crítico, seria a única maneira, segundo Schwarz, de se alcançar a possibilidade de uma totalização conceitual antissistêmica, na qual a experiência histórica da periferia é tomada como momento sintomático da cena global contemporânea.

Já não caberia mais ao intelectual brasileiro "salvar o país", e tampouco abandoná-lo, mas sim pensá-lo especificando o seu lugar na ordem global, empresa para a qual apenas o horizonte 
das classes subalternas poderia dar guarita. Aí está um dos paradoxos da negatividade periférica schwarziana: a crítica deve ser independente e empenhada ao mesmo tempo, a primeira característica tornando-se condição de possibilidade da segunda (cf. Querido, 2019a). Ora, como solucionar na prática intelectual essa difícil equação a não ser pelo recurso duvidoso à genialidade e ao senso de compromisso do próprio crítico?

Em entrevista de 1987, republicada em Seja como for, Schwarz afirma:

Todo autor que se preza, quando pega a caneta, quer indicar entre outras coisas a hora histórica. Isso vale tanto para o ficcionista, como para o poeta, como para o crítico. A luta pela identificação e pela definição do que seja o atual está no centro da arte moderna. Acontece que a hora histórica não é convencional como a hora do relógio. Nem por isso ela é arbitrária. Mas é fato que a resposta, por mais estudada e fundamentada que seja, sempre contém algo de engajamento, algo de aposta no futuro, sem o que a crítica de arte é anódina. (p.48)

Explicitar esse paradoxo - o do intelectual independente sem concessões, mas engajado no destino das classes subalternas - é um dos muitos méritos de Schwarz, esse espírito ígneo cujo brilho se faz tanto mais presente conforme avança o ofuscamento bárbaro que se produz no Brasil (e no mundo) contemporâneo.

\section{Referências}

JACOBY, R. Os últimos intelectuais: a cultura americana na era da academia. Trad. Magda Lopes. São Paulo: Trajetória Cultural; Edusp, 1990.
QUERIDO, F. M. Nacional por negação: ensaio e "crítica independente" no último Roberto Schwarz. Revista do IEB (USP), São Paulo, n.74, p.233-49, 2019a. . Pensamento ao quadrado: Roberto Schwarz e o Brasil. Lua Nova, São Paulo, n.107, p.235-61, 2019b.

SCHWARZ, R. Seja como for. Entrevistas, retratos e documentos. São Paulo: Duas Cidades; Ed. 34, 2019. 448p.

Fabio Mascaro Querido é professor do Departamento e do Programa de Pós-Graduação em Sociologia da Unicamp. @ - fabiomascaro@yahoo.com.br / https://orcid.org/0000-0003-1648-5615. Recebido em 30.4.2020 e aceito em 4.5.2020.

I Universidade Estadual de Campinas, Programa de Pós-Graduação em Sociologia, Campinas, São Paulo, Brasil. 